\title{
Participation Barriers in Recreational Walking Activity Gaziantep
} Sample

\author{
Yilgin Ahmet ${ }^{*}$, Alpullu Aytekin \\ Marmara University Faculty of Sport Sciences, Istanbul, Turkey \\ Study Area: Gaziantep, Turkey \\ Coordinates: $37^{\circ} \mathrm{O} 4^{\prime} \mathrm{N} ; 37^{\circ} 23^{\prime} \mathrm{E}$
}

Key words: Recreation, Park, Urban Forest.

\section{Introduction:}

Urban life, which basically treats people as a value, while its level of welfare creates an opportunity for leisure in the individual, on the other hand, it greatly suppressed the interaction of the human with its environment and therefore, people's health problems have arisen. In society, although health problems are mostly perceived physically, there are many psychological and social symptoms. In this context, as improvements in living standards increase in parallel with technological developments, individuals need higher quality leisure time and prefer to participate in hiking and similar outdoor activities where breathing problems are experienced less (Marafa \& Tung, 2004). Especially in cross-sectional studies conducted in urban parks and recreational areas, they show that activities in open areas are supportive of depression, mental and physical health. Sporty conscious people prefer parks and urban forests for activity purposes because they prefer the green area when they have the opportunity and also they believe in its effect on mental health and respiratory system

\section{Abstract}

Our research aims to examine the participation barriers of individuals who have recreational walking activities in parks and urban forests. The "Recreation Area Participation Barriers" (RAKE) scale was used to identify recreation area participation barriers. The scale consists of 17 items. These items consist of five sub-dimensions and these subdimensions can be listed as "security", "time", "friend", "sports field" and "individual barriers". A total of 309 ( $\mathrm{x}^{-}$: 1.48) people, 162 women and 147 men, who took a walk in parks and urban forests of the Gaziantep region participated in the study. Besides, when the education level, working status and safety sub-dimension were compared, it was found that there was a statistically significant difference. No statistical difference in the comparisons between the age and sports area sub-dimension and the total scale. It was found that women experience the participation barriers of recreation area activities in terms of security, time and individual factors more than men, and when compared to the education level, it is understood that those in the undergraduate and associate degree education levels have more security concerns than the high school level, and civil servants give more importance to security than those working in the private sector.

and a positive perspective on social relations.

Although the purposes of recreation area differ among individuals, it usually enables the individual to cope with many problems in returning to his daily busy business life, as it has a positive effect on the feeling of relaxation and renewal (Gümüs \& Özgül, 2017). People tend to choose parks and urban forests in carrying out walking activities in order to develop different perspectives and life skills by increasing their relationships with others and gaining new experiences. In studies conducted, it is stated that green areas have a key potential in developing mental health problems arising from environmental factors that society is exposed to (Astell-Burt \& Feng, 2019).

It is a decisive factor that individuals know their ability to complete this action within their comfort zone in participating or avoiding walking physical activity (Coetzee, 2018). Individuals devote more time to such activities because of improving mental and physical health and because of the belief that engaging in outdoor physical activity is essential to health among recreational activities (Swarbrooke et al., 2003). The activities and uses between

*Corresponding Author: ahmetyilgin@kilis.edu.tr 
the beginning and ending point of walking action by (Yin, 2013) are expressed as in Figure 1, where road components listed as accessibility, socialization, security, and image affect walkability (Tekel \& Tamer, 2016).

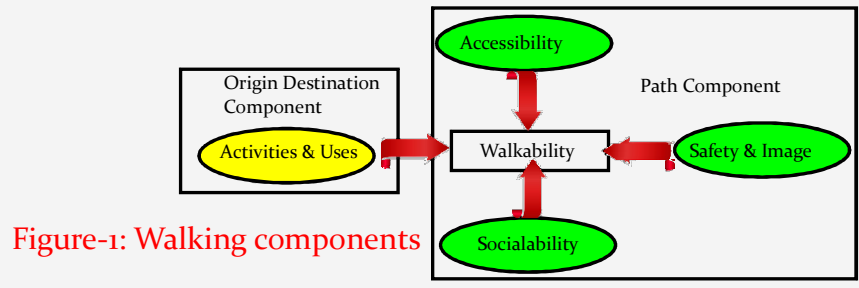

(Yin, 2013) "Assessing Walkability in the City of Buffalo: Application of Agent-Based Simulation", Journal of Urban Planning and Development, 139, 166-175.

There are some obstacles in physical activities that individuals want to do in recreation areas. Classification of these barriers according to the hierarchical model made by (Crawford \& Godbey, 1991). Leisure time barriers are personal (intrapersonal), interpersonal, and structural (structural) barriers (Çetinkaya et al., 2016). Participation barriers in recreation areas can be summarized as follows:

Security barrier; Concerns, worries, and fears related to physical, psychological, social, and other environmental problems related to the area where the activity will be performed.

Leisure time barriers; are factors that prevent the individual from participating in the activity and enjoying their leisure time (Çetinkaya et al., 2016).

The barrier of friends; The need to act as a social entity with other individuals and groups is to restrict the desire to compare, compete, and solidarity with their physical and spiritual actions.

Sports field barriers; It is the previous experience and thoughts of the individual that he/she can be comfortable while doing his/her interests and needs and skills, and that organized and developed sports equipment and equipment are not availableat the expected level.

Individual barriers; affecting the individual's leisure time preferences; stress, fear, shame, depression, anxiety, group attitudes, perceived skill, and perceived suitability forvarious leisure activities (Çetinkaya et al., 2016).

Interpersonal barriers; Family, friends, spouse, or other people expressing the suitability of the social environment where the activities are performed are social factors (Çetinkaya et al., 2016).

Structural obstacles; transportation, economic, time, season, business life, climate, family life cycle, and the availability of opportunities are external sources (Çetinkaya, et al., 2016).

In the pursuit of leisure and recreation, attempts to satisfy their higher-level needs, starting from the lower level, vary depending on people's attitudes, past experiences according to their life stages, demographic structures, and socio-economic factors (Marafa et al.,
2007). Night walks, walks in the valley and mountains, walks in snow and desert environments, which are included in the physical activity of walking, but it's necessary to mention that some of these activities were considered as adventure activities in many studies. Experience is at the forefront of adventure activities. The main features of the adventure experience are that it is done in a natural environment, contains various risk and danger factors, the results are uncertain and it is affected by the structure of the participants (Ewert, 2000).

Walking activity in open areas is expressed as travel (Ryan, 1998) and because of this reason, it is mostly associated with tourism. Walking among people's travels for various reasons is among the sine qua non. Wu \& Pearce (2014) state that anxiety and relaxation and safety and security needs are the first choices of individuals at the motivation levels that determine the travel career of individuals (Kocabulut, 2017). It was determined by (Shores et al., 2007) lack of information, the distance of recreation area, family obligations, family members with health problems, budget status, and lack of friends to participate in the activity as factors affecting their participation in outdoor recreation activities in North America. In addition, they stated that fear of crime, lack of material, high entrance fees as high-level obstacles, and the negligence of theareas as medium level obstacles (Çetinkaya et al., 2016).

In the studies conducted in the field of recreation participation barriers, it is stated that people prefer different areas in terms of sportive recreation, especially in terms of walking, adults prefer places where there are trees and canopy density instead of plain, flat, grassy areas (Astell-Burt \& Feng, 2019). Social benefit is provided as a result of the impact of social, cultural, and physical recreation activities in urban forests and parks, where green areas are intensely preserved in health protection.

This study is limited to the city center of Gaziantep and includes participation barriers in relation to the places where individuals exercise regularly for recreation at least three days a week, in parks, urban forests, or both. Gaziantep is one of the cities where immigrants from the East and Southeast Anatolia Region migrate and also refugees from border countries such as Syria, Iraq, and Iran are the most intense. For this reason, the city center contains a very cosmopolitan life. Just having different ethnic elements and fast population growth among the refugees is a sociological case. For example; According to a survey conducted by the Disaster and Emergency Management Presidency (AFAD, 2017). In May 2017, it is stated that refugees residing in Gaziantep province are 37.880 people inside the camp, 293.531 people outside the camp, and 331.411 people in total. Due to the different life culture and possible risks, the increase in immigration and refugees cause the use of recreational activities to narrow. Especially the Covid-19 virus epidemic and similar 
infectious diseases that affect the whole world, the inadequate opportunities compared to the population in terms of recreation and exercise areas, and the local picnic habits and other problems constitute an obstacle for individuals to walk for physical activity.

In our study, we aimed to reveal the factors affecting recreation area participation barriers in individuals performing physical activity for sport recreation in the Gaziantep region. The main problem of the research is to try to understand the participation barriers that individuals show sensitivity in walking physical activity. Accordingly, in the recreation area participation barriers:

- Is there a difference between the gender variable and its scale and sub-dimensions?

- Is there any difference between the age variable and its scale and sub-dimensions?

- Is there a difference between the education level and the scale and sub-dimensions?

- Is there a difference between income level and scale and subdimensions?

- Is there a difference between working status and scale and sub-dimensions?

- Is there any difference between the walking area preference scale and sub-dimensions?

In the study, it is revealed how the factors that prevent participation in walking physical activity in parks and urban forests have an effect on individuals. In this context, it is thought that local governments will realize what the potential participation barriers are in the region and will be beneficial in terms of scientific knowledge.

\section{Methodology:}

In this study, the "Recreation Area Participation Barriers" (RAKE) scale developed by (Gümüs \& Özgül, 2017) was used to determine the recreation area participation barriers of individuals who exercise physical activity for walking in the Gaziantep region. The scale was tested in a five-point Likert type (1: strongly disagree, 5: strongly agree) with 17 items and 5 sub-dimensions (security barrier, time barrier, friend barrier, sports field barrier, and individual barrier) and its validity and reliability $(\alpha: 85)$. Permission was obtained from the ethics committee (Marmara Unıversity Health Sciences Institute Ethics Committee, no 185) and researchers regarding the study.

In the study, it was planned to obtain crosssectional data specific to the parks and urban forests where walking activity was performed in line with the screening model based on the descriptive research method. The simple random survey method was applied by combining the expressions on the RAKE scale regarding the independent variables such as gender, age, education, income level, working status, and activity preference area in data generation.

The population of the study consists of individuals at the age of 18 and over who regularly walk at least three days a week in parks and urban forests in the Gaziantep region. It has been determined that the average number of people who come only for walking physical activity in the urban forest is between 50 and 200 per day and more individuals participate, especially at the weekend. In parks, it is thought that the number of individuals is quite difficult to measure, but it is thought that it is between $400-800$ per day according to weather conditions. For this reason, the universe is estimated to be about 800 people. A total of 309 people who voluntarily participated in the study constituted the sample group. According to Yazıcıoğlu \& Erdoğan (2004), considering the 95\% confidence interval and $05 \%$ sample error ( $\mathrm{N}: 100.000$ and $\mathrm{n}: 384)$, the sample was considered to be sufficient.

This study included 309 individuals aged 18 and over who take their regular walks in parks and urban forests on different days of the week. The study consists of 162 women and 147 men who voluntarily participate. Information about the participants is given in Table 3.

In this study, statistical tests were carried out using the statistical analysis program SPSS 15 . The reliability of the scale is indicated in Table 1 . The test results for the data set to be similar to the scale and the analysis methods to be followed in the study are given in Table 2. Accordingly, it was decided to conduct parametric test analyzes, to apply percentage, frequency, and averages in demographic information, t-test in binary comparisons, and variance (ANOVA) test in multiple comparisons.

\begin{tabular}{|c|c|c|c|}
\hline Scale \& Sub-Dimensions & C's $\alpha$ & Work & C's $\alpha$ \\
\hline Total (17 Items) & $\alpha: 85$ & Total (17 Items) & $\alpha: 87$ \\
\hline Security Barr.(1-2-3-4) & $\alpha: 91$ & Security Barr. $(1-2-3-4)$ & $\alpha: 87$ \\
\hline Time Barr. $(5-6-7)$ & $\alpha: 82$ & Time Barr. $(5-6-7)$ & $\alpha: 78$ \\
\hline Friend Barr. $(8-9-10)$ & $\alpha: 86$ & Friend Barr. $(8-9-10)$ & $\alpha: 75$ \\
\hline Sports Area Barr. (11-12-13) & $\alpha: 87$ & Sports Area Barr. (11-12-13) & $\alpha: 81$ \\
\hline Individual Barr. (14-15-16-17) & $\alpha: 84$ & Individual Barr. (14-15-16-17 & $\alpha: 72$ \\
\hline
\end{tabular}

When we examine Table 1 , it can be seen that RAKE scale reliability Cronbach's Alpha in total scale $\alpha$ : 85 - study $\alpha: 87$, in the security barrier $\alpha: 91$ - in the study $\alpha: 87$, in the time barrier $\alpha: 82$ - in the study $\alpha: 78$, in the friend barrier $\alpha: 86$ - in the study $\alpha: 75$ sports field obstacles $\alpha: 87$ - study $\alpha: 81$ and individual obstacle $\alpha: 84$ - study $\alpha: 72$. It is understood that the reliability coefficient stated in the use of the scale by Gumuş \& Özgül (2017) has similar results and can be used for this study. In studies conducted in the literature, it is stated that the value of $\alpha$ is $0.61<\alpha$ o.8o with medium reliability and the scale between $0.81<\alpha 1.00$ is high, and if the coefficient calculated for the scale is over o.9o, there may be unnecessary questions in the scale (Kilic, 2016), (Table-1).

As per Table-2 in the RAKE scale data set obtained from 309 people related to the study, in terms of normality and homogeneous distribution, the total scale was found to be skewness-0,138 and kurtosis 0,150 and Levene test as 0.879 
for homogeneous distribution of variances. In the subdimensions, it was observed that the security barrier was skewness 0.1170 and the kurtosis -0.967 and the Levene test 0.879 , the time barrier skewness - 0.181 and the kurtosis 0.829 and the Levene test 0.087 . It was seen that friend barrier skewness 0,102 and the kurtosis-0,837 and the Levene test 0,966 , sports area barrier skewness-0,102 and the kurtosis-o,816 and the Levene test 0,533, individual barrier skewness-0,201 and the kurtosis-0,429 and the Levene test 0,527 . As a result of the analysis, it is understood that the data set meets the assumptions of parametric analysis by taking into account that the number of participants with normal distribution and homogeneous distribution is 309 .

Table-2: Normal Distribution and Homogeneous Distribution Tests of Variances in Data

\begin{tabular}{lllllllll}
\hline $\mathrm{a}$ & $\mathrm{b}$ & $\mathrm{c}$ & $\mathrm{d}$ & & $\mathrm{e}$ & \multicolumn{2}{l}{$\mathrm{f}$} \\
\hline Total & -.138 & .150 & 309 & .079 & 309 & .074 & .879 \\
Security Barrier & .170 & -.967 & 309 & .000 & 309 & .000 & .122 \\
Time Barrier & -.181 & -.829 & 309 & .000 & 309 & .000 & .087 \\
Friend Barrier (8-9-10) & .102 & -.837 & 309 & .000 & 309 & .000 & .966 \\
Sports Area Barrier (11-12-13) & -.102 & -.816 & 309 & .000 & 309 & .000 & .533 \\
Individual Barrier (14-15-16-17) & -.201 & -.429 & 309 & .000 & 309 & .000 & .527 \\
\hline
\end{tabular}

$\mathrm{a}=$ Scale and Sub-Dimensions; $\mathrm{b}=$ Skewness (Skewness); $\mathrm{c}=$ Kurtosis (Kurtosis) $\mathrm{d}=$ Kolmogrov-Smirnova; e=Shapiro-Wilk; $\mathrm{f}=$ =Variance Distribution (Levene Statistic)

\section{Results:}

In the study, frequency and percentage analyzes and findings related to the variables in the personal characteristics of the participants are indicated in the tables.

Table-3: Analysis of Results of Demographic Variables

\begin{tabular}{|c|c|c|c|c|c|}
\hline Gender $(\mathrm{x}=1.48)$ & $\mathrm{N}$ & $\%$ & Age $(x=1.04)$ & $\mathrm{N}$ & $\%$ \\
\hline Female & 162 & 52.4 & 18-65 Years & 297 & 96.1 \\
\hline Male & 147 & 47.6 & 66-79 Years & 12 & 3.9 \\
\hline Training $(\mathrm{x}=1.77)$ & & & Comes $(x=1.77)$ & & \\
\hline High school \& under & 102 & 33.0 & Minimum Wage & 115 & 37.2 \\
\hline $\begin{array}{l}\text { Undergraduate \& } \\
\text { Associate Degree }\end{array}$ & 175 & 56.6 & 3000-5000 TL & 141 & 45.6 \\
\hline Graduate & 32 & 10.4 & $>5001 \mathrm{TL}$ & 53 & 17.2 \\
\hline Work $(\mathrm{x}=1.83)$ & & & Walking Prefere & $(x=1$. & \\
\hline Government & 127 & 41.1 & Parks & 141 & 45.6 \\
\hline Private & 106 & 34.3 & Urban Forests & 48 & 15.5 \\
\hline Not working & 76 & 24.6 & Park \& Urban & 120 & 38.8 \\
\hline Total & 309 & 100 & Forest & 309 & 100 \\
\hline
\end{tabular}

When Table-3 is self-explanatory.

As per Table-4 it was understood that female individuals perceived more obstacles than men in terms of total scale, safety, time and individual disability according to the mean scores between women and men in terms of differentiation.

As per Table-5, the parameter tested are not statistically significant.

According to the "education level" variable, the Tukey HSD test was performed with one-way analysis of variance in the Barriers to Participation in Recreation Activities
(RAKE) scale and its sub-dimensions.

No significant difference between the groups for the dimensions.

There was a significant difference between groups in the Security Barrier sub-dimension. It was understood by Tukey HSD that the significant difference was between individuals with High School and below and Bachelor and Associate education levels. It was revealed that individuals with undergraduate and associate education levels give more importance to security than individuals with high school and lower education levels.

Table: 4 Gender Variable T-Test Results

\begin{tabular}{lllllll}
\hline Dimension & Gender & $\mathrm{N}$ & $\mathrm{x}$ & $\mathrm{Ss}$ & $\mathrm{T}$ & $\mathrm{P}$ \\
\hline Total Scale & Female & 162 & 3.0490 & .73880 & 2.796 & $.005^{*}$ \\
& Male & 147 & 2.8123 & .74786 & & \\
Security & Female & 162 & 2.9522 & 1.21760 & 2.808 & $.005^{*}$ \\
Barrier & Male & 147 & 2.5765 & 1.12438 & & \\
Time Barrier & Female & 162 & 3.1975 & 1.01238 & 2.757 & $.006^{*}$ \\
& Male & 147 & 2.8662 & 1.09979 & & \\
Friend & Female & 162 & 2.8457 & 1.08069 & 1.431 & .153 \\
Barrier & Male & 147 & 2.6689 & 1.08784 & & \\
Sports Area & Female & 162 & 3.1687 & 1.06532 & .170 & .865 \\
Barrier & Male & 147 & 3.1474 & 1.14019 & & \\
Individual & Female & 162 & 3.0972 & .93053 & 2.230 & $.026^{*}$ \\
Barrier & Male & 147 & 2.8639 & .90434 & $*$ P<0.05; N (309)
\end{tabular}

Table-5: Age Variable T-Test Results.

\begin{tabular}{lllllll}
\hline Dimension & Age & $\mathrm{N}$ & $\mathrm{x}$ & $\mathrm{Ss}$ & $\mathrm{T}$ & $\mathrm{P}$ \\
\hline Total Scale & $18-65 \mathrm{yrs}$ & 297 & 2.9420 & .75520 & .646 & .519 \\
& $66-79 \mathrm{yrs}$ & 12 & 2.7990 & .66051 & & \\
Security & $18-65$ & 297 & 2.7988 & 1.19107 & 1.876 & .062 \\
Barrier & $66-79 \mathrm{yrs}$ & 12 & 2.1458 & .91985 & & \\
Time Barrier & $18-65 \mathrm{yrs}$ & 297 & 3.0382 & 1.07212 & -.144 & .886 \\
& $66-79 \mathrm{yrs}$ & 12 & 3.0833 & .94415 & & \\
Friend Barrier & $18-65 \mathrm{yrs}$ & 297 & 2.7508 & 1.09395 & -.866 & .387 \\
& $66-79$ yrs & 12 & 3.0278 & .85821 & & \\
Sports Area & $18-65 \mathrm{yrs}$ & 297 & 3.1661 & 1.09123 & .598 & .550 \\
Barrier & $66-79$ yrs & 12 & 2.9722 & 1.33680 & & \\
Individual & $18-65 \mathrm{yrs}$ & 297 & 2.9882 & .92718 & .186 & .852 \\
Barrier & $66-79$ yrs & 12 & 2.9375 & .87986 & &
\end{tabular}

Table-6: Education Level Variable One Way ANOVA Results

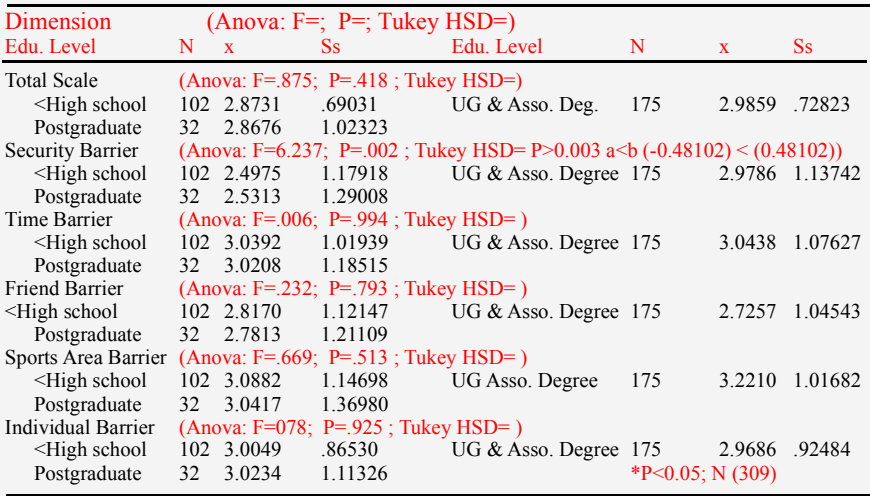

As per the "income level" variable, the Tukey HSD test was performed with one-way analysis of variance in the Barriers to Participation in Recreation Activities (RAKE) scale and its sub- 


\section{ORIGINAL ARTICLE}

dimensions. No significant difference between the groups for the dimensions.

Table-7: Income Level Variable One Way ANOVA Results.

\begin{tabular}{|c|c|c|c|c|c|c|}
\hline \multirow[t]{2}{*}{ Dimension } & \multirow[t]{2}{*}{ Income Level } & & $\mathrm{X}$ & \multirow[t]{2}{*}{ Ss } & \multicolumn{2}{|c|}{ Anova } \\
\hline & & \multicolumn{2}{|c|}{ Variable } & & & $\mathrm{P}$ \\
\hline \multirow[t]{3}{*}{ Total Scale } & Min. Wage & 115 & 2.9877 & .70818 & \multirow{3}{*}{\multicolumn{2}{|c|}{$\begin{array}{ll}1.151 & .318\end{array}$}} \\
\hline & $3000-5000 \mathrm{TL}$ & 141 & 2.9458 & .75488 & & \\
\hline & $\geq 50$ & 53 & 2.8002 & .82743 & & \\
\hline Security & Min. Wage & 115 & 2.8935 & 1.14663 & \multirow{3}{*}{\multicolumn{2}{|c|}{2.008 .136}} \\
\hline \multirow[t]{2}{*}{ Barrier } & $3000-5000 \mathrm{TL}$ & 141 & 2.7784 & 1.20197 & & \\
\hline & $\geq 500$ & 53 & 2.5000 & 1.21192 & & \\
\hline \multirow[t]{3}{*}{ Time Barrier } & Min. Wage & 115 & 3.1072 & 1.02269 & \multirow{3}{*}{1.437} & \multirow[t]{3}{*}{.239} \\
\hline & $00 \mathrm{TL}$ & 141 & 3.0686 & 1.09365 & & \\
\hline & $\geq 500$ & 53 & 2.8176 & 1.07530 & & \\
\hline Friend & Min. Wage & 115 & 2.7826 & 1.12147 & \multirow[t]{3}{*}{.034} & \multirow[t]{3}{*}{.966} \\
\hline \multirow[t]{2}{*}{ Barrier } & $3000-5000 \mathrm{TL}$ & 141 & 2.7494 & 1.04543 & & \\
\hline & $\geq 500$ & 53 & 2.7484 & 1.21109 & & \\
\hline Sports Area & Min. Wage & 115 & 3.1913 & 1.07066 & 1.025 & .360 \\
\hline \multirow[t]{2}{*}{ Barrier } & $3000-5000 \mathrm{TL}$ & 141 & 3.2057 & 1.11031 & & \\
\hline & $\geq 50$ & 53 & 2.9623 & 1.13352 & & \\
\hline Individual & Min. Wage & 115 & 2.9935 & .95769 & \multirow[t]{3}{*}{.028} & \multirow[t]{3}{*}{.973} \\
\hline \multirow[t]{2}{*}{ Barrier } & 3000-5000 TL & 141 & 2.9734 & .84974 & & \\
\hline & $\geq 5001 \mathrm{TL}$ & 53 & 3.0047 & 1.04983 & & \\
\hline
\end{tabular}

Table-8: Working State Variable One Way ANOVA Results

\begin{tabular}{lllllll}
\hline Dimension & Working & N & x & Ss & \multicolumn{3}{l}{ Anova } \\
& Status & & & & F & P \\
\hline Total Scale & Government & 127 & 3.0042 & .77827 & 1.000 & .369 \\
& Pvt. Sector & 106 & 2.8657 & .75491 & & \\
& Workless & 76 & 2.9218 & .69822 & & \\
Security & Government & 127 & 3.0079 & 1.23440 & 4.786 & $.009 *$ \\
Barrier & Pvt. Sector & 106 & 2.5377 & 1.13168 & & \\
& Workless & 76 & 2.7105 & 1.12254 & & \\
Time & Government & 127 & 3.1286 & 1.11906 & 1.441 & .238 \\
Barrier & Pvt. Sector & 106 & 2.8994 & 1.04418 & & \\
& Workless & 76 & 3.0877 & .99684 & & \\
Friend & Government & 127 & 2.7848 & 1.11549 & .065 & .937 \\
& Pvt. Sector & 106 & 2.7579 & 1.11130 & & \\
& Workless & 76 & 2.7281 & 1.01063 & & \\
Sports Area & Government & 127 & 3.1391 & 1.12956 & .832 & .436 \\
& Pvt. Sector & 106 & 3.0849 & 1.12128 & & \\
Individual & Workless & 76 & 3.2939 & 1.01830 & & \\
Barrier & Government & 127 & 2.9705 & .96651 & 1.175 & .310 \\
& Pvt. Sector & 106 & 3.0849 & .89568 & & \\
& Workless & 76 & 2.8750 & .88741 & $*$ * P<0.05; N (309)
\end{tabular}

The Tukey HSD test was performed "working status" variable, with one-way analysis of variance in the Barriers to Participation in Recreation Activities (RAKE) scale and its sub-dimensions. As a result, there was no significant difference between the groups for the dimensions. There was a significant difference between groups in the Security Barrier sub-dimension. By Tukey HSD the significant difference was rvealed between individuals working for the Government and Private Sector. The individuals working in government institutions give more importance to security than individuals working in the private sector.
Ambient Science, 2020: Vol. 07(Sp1); 258-264 DOI:10.21276/ambi.2020.07.sp1.oa35

Table-9: Walking Area Preference Variable One Way ANOVA Results.

\begin{tabular}{lllllll}
\hline Dimension & Walking area & $N$ & x & Ss & \multicolumn{3}{l}{ Anova } \\
& preference & & & & F & P \\
\hline Total Scale & Park & 141 & 2.9453 & .74402 & .533 & .587 \\
& Urban Forest & 48 & 3.0221 & .74205 & & \\
& Park \& Urban & 120 & 2.8917 & .76624 & & \\
Security & Park & 141 & 2.7837 & 1.24256 & 1.105 & .333 \\
Barrier & Urban Forest & 48 & 2.9792 & 1.22890 & & \\
& Park \& Urban & 120 & 2.6792 & 1.09965 & & \\
Time & Park & 141 & 3.0946 & 1.04981 & .575 & .563 \\
Barrier & Urban Forest & 48 & 3.0833 & 1.04395 & & \\
& Park \& Urban & 120 & 2.9583 & 1.09712 & & \\
Friend & Park & 141 & 2.7660 & 1.07478 & .238 & .788 \\
Barrier & Urban Forest & 48 & 2.6667 & 1.07629 & & \\
& Park \& Urban & 120 & 2.7944 & 1.10949 & & \\
Sports Area & Park & 141 & 3.0733 & 1.10417 & .780 & .459 \\
Barrier & Urban Forest & 48 & 3.2222 & .97081 & & \\
& Park \& Urban & 120 & 3.2333 & 1.14381 & & \\
Individual & Park & 141 & 3.0337 & .91477 & 1.756 & .175 \\
Barrier & Urban Forest & 48 & 3.1354 & .90501 & & \\
& Park \& Urban & 120 & 2.8708 & .93653 & $*$ P<0.05; N (309)
\end{tabular}

How far the "walking area preference" variable was concerned,the Tukey HSD test was performed with oneway analysis of variance in the Barriers to Participation in Recreation Activities (RAKE) scale and its sub-dimensions. As a result, it was understood that there was no significant difference between the groups for the dimensions.

\section{Discussion and Conclusion:}

In this research, it is stated that the factors affecting the recreation area participation barriers in individuals doing physical walking as a sportive activity. As per result, it can be stated that as the education level of the individuals in the sample increases, the income level increases, and local governments build more useful parks according to the needs of the society and that individuals working for the government and having high financial means are more conscious than other parts of the society. Unlike this study, in different studies conducted by (Armutcu, 2018; Yilgin, 2019). It was stated that although the people who use the parks are mostly women, their education and income levels are slightly lower than this study. It is stated that individuals decide on leisure time activities according to their gender, age, income, physical and personality structure, education and skills, family interactions, and social environment values (Gümüs et al., 2017).

When the gender variable averages were examined, most of the factors were higher than the men. (Table 4). It was understood that women perceived more obstacles than men in terms of total scale, security, time, and individual barriers. In a similar study, (Armutcu, 2018) commented that women resulted from feeling more insecure in society than men. Çapak (2019) found no significant difference in terms of genders in factors preventing the participation of 
academic staff and students from recreational activities. Çetinkaya et al. (2016) stated that although genders are affected similarly in free time participation barriers, women face more obstacles because of their social roles, maledominant social pressure, women being physically weak, perceived as sexual objects, and their responsibilities at home. With no significant difference in the age variable in the participants, it is understood that there are similar thoughts in recreation area participation barriers in terms of age scale and sub-dimensions. In a different study, it was stated that due to the personal restrictions caused by old age, there are more obstacles among the age groups because the elderly prefer more passive activities compared to young people, and also the financial structure of individuals constitutes an obstacle according to this study (Çetinkaya et al., 2016).

While the education level of the individuals raises the standard of living, it ensures that they are more conscious about the family, work-life, and social environment in their inner world and improves their awareness of these issues. In terms of education level, it has been understood that there is no difference in terms of total scale, time, friends, sports area, and individual barriers among participation barriers of participation in a recreation activity. Also, when we look for the security barrier scale, it is understood that as the level of education increases, the sensitivity to security increases (Table 6). In studies conducted on the physical activity levels of individuals, it was stated that as the level of education increases, the participation in physical activities increases in adults and elderly individuals (Memis \& Yildiran, 2007). Fogelman et al. (2004), stated that half of the participants lead a sedentary lifestyle and individuals with low education at work have higher physical activity levels, while individuals at higher education level have higher levels of leisure physical activity. Although security is an important obstacle, in contrast to the findings obtained by Gümüs et al. (2017) that personal safety is an important obstacle in the use of parks and recreation areas, the number of lighting and security personnel of recreation areas should be increased, and those with a low level of education face more participation barriers. However, in the same study, it was stated by (Searle \& Jackson, 1985). That the level of participation decreases as the level of education increases (Yorucu et al., 2017).

In terms of income level, there was no significant difference between the participants. It is thought that the majority of the participants in the high-income level in terms of the regional settlement, which is among the limitations of the study, does not cause differentiation among the participants (Table 7 ).

The majority of the individuals using the park and urban forests are those working in the government institution and the private sector. When the obstacles related to the participation of individuals are analyzed, it is understood that there is no difference in terms of time, friends, sports area, and individual barrier in the total scale, but in the security dimension, employees working in the government institutions prioritize security more than private-sector employees (Table-8). The need for security was stated in the second step according to the hierarchy of needs put forward by (Maslow, 1943). As well as the individual's desire to live in a safe environment free from conflicts and confusion (Kula \& Çakar, 2015). The main security problems in parks are caused by other individuals and some objects. It is stated that being safe is seen as a social need and therefore it also requires looking at this concept on the state axis (Özgür \& Erciyes, 2017). In this context, it is thought that those working in government institutions follow the events in society more closely in terms of security.

The places where walking physical activity is most comfortable for the purpose are generally parks and urban forests. In the study, it was understood that parks are preferred among individuals' preferences, but there are also some use the urban forest. It is believed that the parks are preferred more due to time, transportation, security, sports equipment, and other factors, but there is no significant difference between individuals in terms of preferences, and the participants have similar attitudes and perceptions to the walking physical activity in parks and urban forests.

As a result, women experience more obstacles in recreation area participation in security, time and individual factors than men, and those in the undergraduate and associate education level at the education level have higher security concerns than those in the high school and under level, and also civil servants have higher security concerns than private-sector employees and in this context, it is understood that local administrations should pay more attention to security needs in parks and urban forests. To support the physical and mental well-being of all segments of the society for the health expenses and workforce of the country, it should be ensured that it can compete with the changing and developing modern world with local and national management and executive policies. For refugees coming to the country originating from the geography we live in, such as migration and the like, the places where the social interactions will be most comfortable are the parks and urban forests so this situation should be considered, and also other measures, especially security, should be reviewed.

\section{References:}

AA.F.A.D. (2017): Demographic Outlook of Syrians in Turkey, Living Conditions and Expectations Towards Future Field Research, T. C. Prime Ministry Disaster and Emergency Management Presidency, Ankara.

Armutcu, F. (2018): Determining The Factors Affecting The Use Of Parks And Recreation Areas For Physical 


\section{ORIGINAL ARTICLE}

Activity. (Master's Thesis, Batman University).

Astell-Burt, T. \& Feng, X. (2019): Association of urban green space with mental health and general health among adults in Australia. LAMA Network Open, 2(7):E198209-E198209.

Coetzee, B.A. (2018): Self-Reported Fitness Levels, Actual Fitness Levels And Recorded Energy Expenditure On Graded Hiking Trails (Doctoral Dissertation, University Of The Free State).

Crawford, D.J.E. \& Godbey, G. (1991): A hierarchical model of leisure constraints. L. Leis. Sci., 13(1991):309-320.

Çapak, E. (2019): Determination Of The Factors Preventing Participation Of The Instructors And Students Of Bingöl University In Recreational Activities (Master's Thesis, Bartin University, Institute Of Social Sciences).

Çetinkaya, G., Yildiz, M. \& Özçelik, M.A. (2016): National park usage barriers in outdoor recreation. Mediter. J. Human., 10:99-114.

Ewert, A.W. (2000): Trends In Adventure Recreation: Programs, Experiences, And İssues. In: Proceedings of the 5 th Outdoor Recreation And Tourism Trends Symposium (pp. 17-20).

Fogelman, Y., Bloch, B. \& Kahan, E. (2004): Assessment of participation in physical activities and relationship to socioeconomic and health factors. Patient Edu. Counsel., 53:95-99.

Gümüș, H. \& Özgül, S.A. (2017): Development of scales for barriers to participation and preference factors in the use of recreation area.J. Hum. Sci., 14(1):865-882.

Gümüs, H., Alay, Ö.S. \& Karakılıç, M. (2017): Factors affecting the choice of place and participation of the users coming to the park and recreation areas for physical activity. Spormetre J. Phys. Edu. Sports Sci., 15(1):31-38.

Kiliç, S. (2016): Cronbach alpha reliability coefficient. Psychiatry Behav. Sci., 6(1):47.

Kocabulut, Ö. (2017): Determination of academicians' motivation to participate in international congresses. L. Travel Hotel Manag., 14(1):48-58.

Kula, S. \& Cakar, B. (2015): The relationship between individuals' perception of security and life satisfaction in the context of Maslow needs hierarchy. Bartın Uni. İ BF J., 6(12):191-210.

Marafa, L.M. \& Tung, F. (2004): Changes in participation in leisure and outdoor recreation activities among hong kong people during the sars outbreak. World Leis. J., 46(2):38-47.
Ambient Science, 2020: Vol. 07(Sp1); 258-264 DOI:10.21276/ambi.2020.07.sp1.oa35

Marafa, L.M., Ting, H.Y. \& Cheong, C.K. (2007): Perceived benefits of hiking as an outdoor recreation activity in Hong Kong. Licere-Revista Do Programa De Pós-Graduação Interdisciplinar Em Estudos Do Lazer, 10(2).

Maslow, A.H. (1943): A theory of human motivation. Psychol. Rev., 50(4):370-396.

Memiș, U.A. \& Yildiran, İ. (2007): Relationship between childhood and adolescent physical activity experiences and adult physical activity levels. Gazi J. Physic. Edu. Sports Sci., 13(1):13-32.

Özgür, E. \& Erciyes, E. (2017): Reflections of the transformation in public administration to the internal security sector. $L$. Secur. Sci., 6(1):79-109.

Ryan, C. (1998): The travel career ladder, an appraisal. Ann. Tour. Res., 25(4):936-957.

Searle, M.S. \& Jackson, E.L. (1985): Socioeconomic variations in perceived barriers to recreation participation among wouldbe participants. Leis. Sci., 7(2):227-249.

Shores K.A., Scott, D. \& Floyd, M.F. (2007): Constraints to outdoor recreation: a multiple hierarchy stratification perspective. Leisure Sci.:An Interdisc. J., 29/3(2007):227-246.

Swarbrooke, J., Beard, C., Leckie, S. \& Pomfret, G. (2003): Adventure Tourism: The New Frontier. Pub. by: Routledge.

Wu, M.Y. \& PEARCE, P.L. (2014): Chinese recreational vehicle users in Australia: A netnographic study. Tour. Manag., 43:22-35.

Yilgin, D. (2019). Master's Thesis Health Beliefs On Sportive Recreational Activities (Gazi antep Sample) Batman University Institute For Social Sciences Recreation Management, (Master's thesis, Batman Üniversity).Yin, L. (2013): Assessing walkability in the city of buffalo:application of agent-based simulation.J. Urban Plan. Dev., 139:166-175

Yurcu, G., Kasalak, M.A. \& Akinci, Z. (2017): Factors Affecting Participation In Recreative Activities In Elderly Individuals. We work with leading authors to develop the strongest academic materials with bringing cutting-edge thinking and best learning practice to a global world., 145 . 